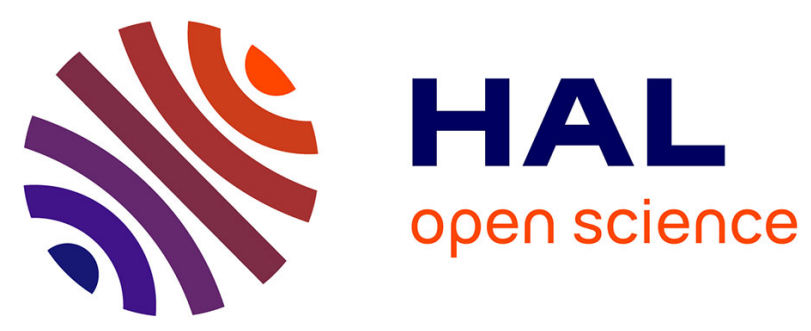

\title{
How are women with SUI-symptoms treated with duloxetine in real life practice? - Preliminary results from a large observational study in Germany
}

Martina Manning, Ursula Gotsch, Anette Minarzyk, Deborah Quail, Gross Andreas, Ines Pages, Hans D Methfessel, M C Michel

\section{To cite this version:}

Martina Manning, Ursula Gotsch, Anette Minarzyk, Deborah Quail, Gross Andreas, et al.. How are women with SUI-symptoms treated with duloxetine in real life practice? - Preliminary results from a large observational study in Germany. International Journal of Clinical Practice, 2009, 63 (12), pp.1724. 10.1111/j.1742-1241.2009.02186.x . hal-00532545

\section{HAL Id: hal-00532545 https://hal.science/hal-00532545}

Submitted on 4 Nov 2010

HAL is a multi-disciplinary open access archive for the deposit and dissemination of scientific research documents, whether they are published or not. The documents may come from teaching and research institutions in France or abroad, or from public or private research centers.
L'archive ouverte pluridisciplinaire HAL, est destinée au dépôt et à la diffusion de documents scientifiques de niveau recherche, publiés ou non, émanant des établissements d'enseignement et de recherche français ou étrangers, des laboratoires publics ou privés. 


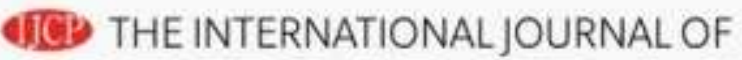 CLINICAL PRACTICE
}

\begin{abstract}
How are women with SUI-symptoms treated with duloxetine in real life practice? - Preliminary results from a large observational study in Germany
\end{abstract}

\begin{tabular}{|r|l|}
\hline Journal: & International Journal of Clinical Practice \\
\hline Manuscript ID: & IJCP-03-09-0167.FT10.R1 \\
\hline Manuscript Type: & Original Paper \\
\hline Date Submitted by the & O4-Jun-2009 \\
\hline Complete List of Authors: & $\begin{array}{l}\text { Manning, Martina; Lilly Deutschland GmbH, Medical } \\
\text { Gotsch, Ursula; Lilly Deutschland GmbH, Medical } \\
\text { Minarzyk, Anette; Lilly Deutschland GmbH, Medical } \\
\text { Quail, Deborah; Eli Lilly UK, Medical Information Sciences } \\
\text { Andreas, Gross; AK Barmbek } \\
\text { Pages, Ines; Klinikum Ludwigshafen } \\
\text { Methfessel, Hans D; Universitätsklinikum Halle } \\
\text { Michel, M; AMC, University of Amsterdam, Dept. Pharmacology \& } \\
\text { Pharmacotherapy }\end{array}$ \\
\hline
\end{tabular}

\section{s ScholarONE \\ Manuscript Central}


3 How are women with SUl-symptoms treated with duloxetine in real life practice? 5

\section{Preliminary results from a large observational study in Germany}

7

8

9 Martina Manning ${ }^{1}$, Ursula Gotsch ${ }^{1}$, Anette Minarzyk ${ }^{1}$, Deborah Quail ${ }^{2}$, Andreas $^{8}$ Aross $^{3}$, 11 Ines Pages ${ }^{4}$, Hans D. Methfessel ${ }^{5}$, Martin C. Michel ${ }^{6}$

$15^{1}$ Lilly Deutschland GmbH, Medical Department, Bad Homburg, Germany

$18^{2}$ Eli Lilly and Company, European Medical Information Sciences, Windlesham, UK

$21^{3}$ AK Barmbek, Hamburg, Germany

22

23

$24{ }^{4}$ Klinikum Ludwigshafen, Ludwigshafen, Germany

$27^{5}$ Universitätsklinikum Halle, Halle, Germany

$30^{6}$ Academisch Medisch Centrum, Amsterdam, Netherlands 31

32

33Corresponding Author:

39Homburg, Germany

40

45Disclosures:

49 Martina Manning, Ursula Gotsch, and Anette Minarzyk are Lilly Deutschland GmbH 50

51 employees, Deborah Quail is an employee of Ely Lilly and Company UK, Andreas 52

${ }_{54}^{53}$ Gross, Ines H. Pages, Hans D. Methfessel and Martin C. Michel are members of a Lilly 55 56 Advisory Board. 


\section{Abstract}

Background: Duloxetine was found safe and effective in the treatment of moderate to 8

9 severe female stress urinary incontinence (SUI) in controlled clinical trials;

${ }_{16}^{15}$ Objectives: To explore use of various initial duloxetine doses by physicians in the 17 18 treatment of female SUI in routine clinical practice and its implications on drug safety 19 20 and patients' subjective impression of effectiveness.

26 part of an ongoing large-scale observational study in Germany. Data collected at 27

39 SUI treatments were observed in $52.2 \%$, comorbidities in $60.4 \%$ of the patients. $90.7 \%$ 40

44 vertigo (1.6\%) were reported most frequently. $52.2 \%$ of patients were initiated on a 45

46 duloxetine dose of $40 \mathrm{mg} /$ day. Only minor differences in patient characteristics, 47

57higher health risk because of old age and multiple comorbidities than in previous 
1

2

3 controlled clinical trials, AE rates were lower, possibly due to the observational

5

6 character of the study and/or the use of rather low doses. Similar AE rates for varying 7

8 initial doses possibly reflect sensible dose-adjustment to individual needs. 
What's known:

5

Duloxetine was found safe and effective in the treatment of moderate to severe female 8 ${ }_{10}^{9}$ stress urinary incontinence in controlled clinical trials. Up-titration over the first two 11 12 weeks of treatment increases the tolerability of duloxetine in the treatment of stress 13 14 urinary incontinence.

15

16

17

18 What's new:

19

20

21 The female SUI-patients documented in this German observational study had a higher 22 23 24 mean age than patients in controlled clinical trials and a high rate of comorbidities. 25

26Primary care physicians and specialists choose very low duloxetine doses for a high 27 


\section{Introduction}

6

7 Urinary incontinence, defined by the International Continence Society (ICS) as "the 8

9 complaint of any involuntary leakage of urine", is associated with substantial impairment 10

14 systems $(1,2,3)$. The risk of developing urinary incontinence increases with age and its 15

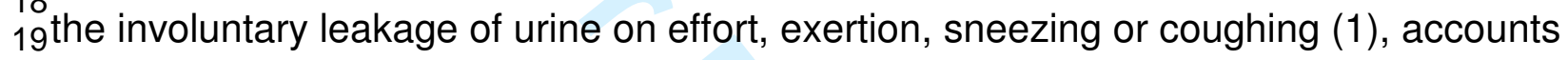
20

21 for approximately half of all urinary incontinence cases experienced by adult women (4; 22

27Duloxetine is the first medication approved in Europe for the treatment of moderate to 28

${ }_{30}^{29}$ severe SUI symptoms. Trials in cats $(7,8,9)$ and healthy female volunteers (10)

32 suggested that the selective serotonin-norepinephrine reuptake inhibitor duloxetine 33

34 enhances the excitability of the pudendal motor neurons and the urethral sphincter 35

36

40Safety data obtained from controlled clinical trials in women with SUI $(11,12,13,14$, 41

47observation due to limited sample sizes. Furthermore, due to restrictive in- and 48

54 treatment of SUI in real life. To explore these issues, DUROSA ("Duloxetine Routine 55 
in February 2005, shortly after the approval of duloxetine for the treatment of SUI in

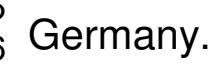

Only a few months later, findings from a randomized study (16) suggested that patients 10 14duloxetine and gradually up-titrated to the recommended dose of $80 \mathrm{mg} /$ day. Dosage 15 ${ }_{19}$ Characteristics. As a consequence, we perceived a demand for data on the handling of 20 21 initial dosage and up-titration from the physicians in clinical practice. Without having 22 ${ }_{24}^{23}$ planned a preliminary evaluation considering this objective, we found that the interim 25 26 safety reports, which were done regularly for this post authorization safety study, did 27 28 provide sufficient data to give an insight into up-titration in everyday clinical practice and 29 ${ }_{31}^{30}$ its results, and decided that these should not be withheld.

\section{Methods}

39 The primary objective of the overall DUROSA study was to evaluate the safety of 40

41 duloxetine in the treatment of women with symptoms of moderate to severe SUI in a 42

46 characterisation of the patient population who receive duloxetine SUI treatment under 47 48
49

53Pharmacovigilance guidelines for post authorisation safety studies, brief progress 54

56 reports were drawn every six months. The data presented in this paper were derived 
8 by mostly office-based urologists, gynaecologists and general practitioners throughout 9 ${ }_{11}^{10}$ Germany. Eligible for documentation were women aged $\geq 18$ years, who received 12 13treatment for SUI symptoms. Patients could be treated with duloxetine (data reported 14 15 here), pelvic floor muscle training (PFMT), pessaries, or any other conservative 17 18 treatment option, but no surgical therapy was to be considered within the duration of the 19 20 study. The choice of treatment was entirely at the discretion of the physician. Adjunct 21

${ }_{23}^{22}$ and combination therapy was acceptable for all patient groups.

26Assuming a sample size of 8,000 duloxetine patients, an uncommon adverse drug 27

31 probability of 0.95 . Thus, with the present sample of 7,888 duloxetine patients, at least 32

3364 patients with an adverse drug reaction that has an incidence of $1 \%$ can be expected 34

39Documentation started with the patient's initiation on a new treatment for SUI (baseline). 40

44 events (AE) was scheduled 4 and 12 weeks after baseline. On request of the EMEA, an 45

46additional 24-week follow-up was introduced as an addendum to the original study

51 amendment applied to patients from primary health care physicians only, who could 52

53 routinely observe their patients over such a long period. Patients from urologist and 55 ${ }_{56}$ gynaecologist practices finished the study with a closing documentation following the 57

5812-weeks scheme (DCF-12). Discontinuation rates therefore needed to be reported 59 
3 separately for patients following the DCF-12 or DCF-24 scheme. Apart from that, for

5 reasons of comparability, we report data on AEs and effectiveness for the entire sample 7

8 as collected until Visit 3 (week 12). The respective results from the 24-week

${ }_{11}^{10}$ observational period as well as those for patients on reference therapy (any other non12. 13 invasive SUI treatment) are not dealt with in this paper and will be published elsewhere. 14

${ }_{17}^{16}$ For analysis, patients treated with duloxetine were assigned to evaluation cohorts by 18 19 initial total daily duloxetine doses as follows: duloxetine initial dose of $20 \mathrm{mg} /$ day 20 21 (Dulox-20), duloxetine initial dose of $40 \mathrm{mg} /$ day (Dulox-40) and duloxetine initial dose of 22 ${ }_{24}^{23} 80 \mathrm{mg} /$ day (Dulox-80), "other" initial doses and duloxetine overall (Dulox-all). The 25 26 analysis was largely descriptive. For quantitative variables (e.g. age) arithmetic means, 27 28 medians, standard deviations, minimum and maximum values, quartiles as well as the 29 30 31 32

33calculated. Qualitative variables were described using absolute and relative frequencies 34

35 (adjusted relative frequencies where appropriate). To assess the rates of AEs in the 37 38 overall duloxetine sample, we evaluated all AEs of DCF-12 patients and of DCF-2439 40 patients with an onset date within 84 days (12 weeks) of Visit 1. Two sided 95\% 41

${ }_{43}^{42}$ confidence intervals $(\mathrm{CI})$ were calculated for the rates of $\mathrm{AEs}$ and serious adverse 44 45 events (SAEs).

${ }_{49}^{48}$ At baseline the following data were collected: patients' age, height, weight, number and 50 51 type of deliveries, duration of SUI symptoms, incontinence episode frequency per week 52

$53($ IEF), number of pads used per week, previous treatment of SUI, whether the patient 54 
8 questioning at all post-baseline visits, including start and stop dates as well as the 9

$11_{11}$ investigator's assessment of causality, and coded according to the Medical Dictionary 12 13 for Regulatory Activities (MedDRA).

21 general satisfaction with current treatment and changes in incontinence episode 22 ${ }_{24}^{23}$ frequency as subjectively perceived by the patients were assessed at every visit after 25 26 baseline. Early discontinuations were reported, including the reasons. The initial daily 27

28 dose of duloxetine was documented at baseline. Duloxetine dosage was reassessed at 29 30 ${ }_{31}$ every following visit, documenting any change.

34DUROSA was conducted according to the ethical principles of the Declaration of 35

39 Goettingen, Germany. The patients provided written consent to the collection and 40 
documentation (i.e. either finished the study or documented early discontinuation). All further data described in this paper are based on this sample.

$94,564(57.9 \%)$ patients were documented following the original protocol of 12 weeks on

14Due to the different schedule, early discontinuation rates of DCF-12 patients and 15

21 discontinued early; 171 (3.7\%) patients from the DCF-12 set and $78(2.3 \%)$ from the 22

${ }_{24}^{23} \mathrm{DCF}-24$ set reported an $\mathrm{AE}$ as reason for discontinuation. Other frequent reasons were:

28 termination of SUI-therapy $(0.8 \%$ / 0.6\%), for DCF-12 and DCF-24 set, respectively.

34 More than half of the duloxetine patients were initiated with doses of $40 \mathrm{mg} / \mathrm{day}(4,121$; 35

39initial doses were given to $59(0.7 \%)$ of the patients. Because of the comparatively 40

45The initial dosage cohorts were similar with respect to age, BMI and parity (Table 2).

${ }_{48}^{47}$ Age ranged between 20 and 96 years. More than half of the patients from all groups

50 were aged 60 years and older (Dulox-all mean \pm SD $61.4 \pm 12.6$, median 62 ); 
$3 \pm 4.3$ (Dulox-80). Corresponding BMI-medians of 26 and $27\left[\mathrm{~kg} / \mathrm{m}^{2}\right]$ indicated overweight

8 deliveries was $2.0 \pm 1.2$ in all initial dosage groups; approximately $10 \%$ of the reported 9

${ }_{11}^{10}$ deliveries were Caesarean sections.

14Mean previous SUI history for Dulox-all was $45.1 \pm 56.0$ months with a median of 27 15

${ }_{17}^{16}$ months; patients from the Dulox-80 group had suffered from previous SUI somewhat 18 19longer than Dulox-20 and Dulox-40 patients (median: 31, 25 and 26 months 20

21 respectively - see overview on baseline data in Table 2). With a median of 10 22

24 incontinence episodes per week, less than half of the patients in this naturalistic setting 25

26 met the criterion of moderate to severe SUI, which was defined as a frequency of $\geq 14$ 27

${ }_{29}^{28} \mathrm{SUI}$ episodes per week in earlier controlled clinical trials $(11,12,13,14,15)$. No

30

31 relevant difference between the initial dosage groups was observed regarding numbers 32

33of incontinence episodes and pads used per week.

36

37 38

39all 4116; 52.2\%, see Table 3). Local hormones and PFMT were the most frequent 40

52Pre-existing concomitant diseases were found in $4764(60.4 \%)$ of the duloxetine 53

${ }_{55}^{54}$ patients; the rates for the initial dose cohorts were all about the same. Overall, the most 
3 frequent comorbidities were hypertension, lipid metabolism disorder and diabetes

6 (Table 4).

${ }_{10}^{9}$ Overall, 3121 (39.6\%) of the duloxetine-patients had seen an urologist, 3126 (39.6\%) ${ }_{12}$ came from general practitioner practices; 1118 (14.2\%) were treated by a

27 practitioners $49.8 \%$ / $20.1 \%$ ), while gynaecologists more often initiated their patients on 28

${ }_{30}^{29}$ the low dose of $20 \mathrm{mg} / \mathrm{day}$ ( $37.5 \%$ vs. urologist $22.8 \%$ and general practitioners $29.3 \%$ ).

33 As Figure 1 shows, $56.0 \%$ of the Dulox-20 patients were taking their initial doses at 34

$38 \mathrm{mg} /$ day). Of the Dulox-40 patients $52.2 \%$ received the initial dose at Week $12,41.3 \%$ 39

40 had been up-titrated, while the rate of patients who received reduced doses was $2.7 \%$. 41

${ }_{3}$ Almost $89 \%$ of the Dulox-80 patients were on the initial dose at Week 12 ; the dose was 44 45 reduced to $40 \mathrm{mg} /$ day in $8.2 \%$ and to $20 \mathrm{mg} /$ day in $0.2 \%$ of the patients. 
${ }_{10}^{9}$ The patients' satisfaction with duloxetine therapy increased over time (Week 4: 20.7

$25(1.2 \%)$. AEs occurring in $\geq 0.5 \%$ of patients are listed in Table 6 . In $4.6 \%$ of all patients,

27 an $\mathrm{AE}$ was associated with early discontinuation.

${ }_{31}$ SAEs were reported in 16 patients $(0.2 \%)$. In $6(<0.1 \%)$ patients SAEs were classified 32

33 as possibly related to duloxetine by the investigator ( 1 nausea and anorexia, 1 gastritis, 34

$380 e d e m a, 1$ vertigo and speech impairment and 1 confusional state plus dermatozoon 39

40 delusion). Three SAEs with lethal outcome occurred in patients on duloxetine within 12 41

45 respectively) and 1 road traffic accident. None of these fatalities was judged as therapy

\section{Discussion}

52

53

54 Including 7,888 women with SUI symptoms, these interim data from the DUROSA study 56 57 are providing a preliminary survey on the use of duloxetine in SUI-treatment under 58 
routine conditions in Germany, with special regard to the characteristics of the typical female SUI-patient population, as well as physicians' dosing habits in relation to 7 8 tolerability and effectiveness.

${ }_{12}^{11}$ Randomised clinical trials investigating duloxetine in the treatment of women with 13 14 symptoms of SUI were mostly conducted with the recommended target dose of 80 15 $16 \mathrm{mg} /$ day $(2 \times 40 \mathrm{mg} ; 11,12,13,14,15)$.

20The present findings from the DUROSA-study showed that under real life conditions 21 ${ }_{23}^{22}$ more than $80 \%$ of the patients were actually initiated with daily doses of less than 24 $2580 \mathrm{mg}$, which is in line with the current recommendation of up-titration. However, these 26

27 low starting doses apparently were not up-titrated to the recommended target dose of 28

${ }_{30}^{29} 80 \mathrm{mg} /$ day in more than half of these patients during the observational period of 12 31 32 weeks. 380ther physician groups. It should be noted, however, that in DUROSA urologists' sites 39

40 were initiated first, and gynaecologists started patient enrolment several weeks later. 41 45 patients might profit from receiving lower duloxetine doses of $40 \mathrm{mg} / \mathrm{day}(2 \times 20 \mathrm{mg})$ for 46

48 the first two weeks, suffering less from nausea or dizziness, which again led to lower 49 50 rates of discontinuation due to AEs compared to patients who started at a full dose of 51 $5280 \mathrm{mg} /$ day. The presentation of these finding at the ICS in Montreal (17) might already 53

${ }_{55}^{54}$ have influenced the physicians' dosing decisions. Shortly afterwards, the data were 
${ }_{10}^{9}$ It is therefore even more remarkable how cautiously physicians of all specialties were 12 adjusting doses from the very beginning, possibly reflecting the physicians' attention to 13 14the perceived individual health risk of the respective patient.

${ }_{18}$ The majority of the patients initiated on 20 or $40 \mathrm{mg} /$ day were content with the 19 20 effectiveness of their treatment at Week 12 of the observational period, though more 21

${ }_{23}^{22}$ than half of them had not been up-titrated. Treatment satisfaction at Week 12 was 24 25 comparably high in all initial dosing cohorts ("very satisfied" or "satisfied": Dulox-20: 26 2788.2\%, Dulox-40: 88.4\%, Dulox-80: 89.9\%).

33 factors for SUI were started with lower duloxetine dosages, but the results from 34 
Overall, more than $60 \%$ of the duloxetine patients reported concomitant diseases, with hypertension, lipid metabolism disorder, diabetes and cardiac disease being the most

8 common. A high rate of multimorbidity must be assumed from the numbers, indicating a

${ }_{11}^{10}$ substantial prevalence of metabolic syndrome.

14The rate of AEs found for duloxetine-patients in DUROSA was notably lower than rates 15

16 reported from previous controlled registration studies (18), which report percentages for 18

19e.g. nausea (DUROSA 5.7\%) between 22.7 (12) and $45.5 \%$ (11, with doses up to 2x60 20

$21 \mathrm{mg} /$ day). Norton (14) however, reported values which are more similar to those found in 22

DUROSA (nausea $13 \%$ for $80 \mathrm{mg}$ over 12 weeks).

27 Overall, the AEs observed under duloxetine treatment in this study did not differ

${ }_{30}^{29}$ substantially from the known safety-profile of duloxetine in the treatment of SUI (19).

32 Most AEs did not lead to early discontinuation, which correlates with the findings of

34 Moore (20), who also reported that the most common adverse reactions to duloxetine, 35

36

37 nausea, fatigue, and dry mouth, were mild to moderate, and did not lead to

38

39 discontinuation as they were mostly transient.

${ }_{43}^{42}$ The initial doses showed less association with the frequency or pattern of AEs in this 44

45 interim sample than expected regarding the results of Castro-Diaz (16). More than $40 \%$ 46

48 of the patients starting with lower doses were up-titrated within the first weeks, and 50 received doses of 40 or $80 \mathrm{mg} /$ day for the further course of the study. This might have 51 52contributed to the small difference in AE-rates associated with the initial doses. 53 ${ }_{55}^{54} \mathrm{Nevertheless,} \mathrm{a} \mathrm{considerable} \mathrm{number} \mathrm{of} \mathrm{patients} \mathrm{who} \mathrm{started} \mathrm{on} 20 \mathrm{mg} /$ day or 56 $5740 \mathrm{mg} /$ day apparently stayed on these doses over the whole course of the study, and 
3 so did more than $80 \%$ of those who started on $80 \mathrm{mg} /$ day (Figure 1 ). The lack of

8 physicians choose lower initial doses for patients deemed more susceptible and 9

${ }_{11}^{10}$ adjusted them very carefully according to the patient's individual needs; such 12. 13 individualised dosing approaches are usually not allowed in the strict setting of 14

15 controlled clinical trials. 16

19 SAEs were rare, given the large case numbers. The AEs judged as therapy-related 20

21 resembled those which had been described previously for duloxetine. None of the SAEs 22

${ }_{24}^{23}$ with lethal outcome were judged related to SUI-therapy, but rather associated with 25 26 cardiovascular disease and old age and can be considered within the normal mortality 27

28 rates for the observed age classes (21).

32 As these interim data were not originally intended for publication, the analysis largely 33

34 lacks indicators of significance. Comparisons of the results in the different initial dose 35

36 37 38

39allowing comparison of the dose cohorts adjusted for baseline differences between the 40

46 assessed categorically, reflecting the patient's subjective impression, which might

${ }_{49}^{4}$ include the perception of a placebo effect. Results from this section therefore should be 50 51 interpreted cautiously. Due to the observational character of this study, a considerable 52

53 number of patients with rather mild SUI were included and treated with duloxetine. 54

${ }_{56}^{55}$ Earlier studies (14) have already reported that in such patients, the effects of duloxetine 
may mingle with a placebo effect of similar size and thus explain the good results for 6 the lower daily doses of 20 and $40 \mathrm{mg} /$ day duloxetine.

13These data from a large observational study show that in routine clinical practice, 14

${ }_{16}^{15}$ physicians are confronted with patients who have a much higher health risk because of 17 18 old age and multiple comorbidities than previously reported in controlled clinical trials. 19

20This might be one explanation why a considerable number of the physicians prescribed 21

22 initial doses which were lower than recommended in the official scheme of up-titration
23 24 25 described in the Summary of Product Characteristics. This cautious adjustment of 26

27 dosing patterns to the particular needs of the individual SUI patient is also reflected by 28

${ }_{30}^{29}$ the comparatively low rate of $\mathrm{AEs}$, though this might also be due to the observational 31 32design of the study. Despite the low doses, a surprising majority of these patients 33

34 reported a considerable reduction of SUI episodes and general satisfaction with their 35 36 37 38 39under naturalistic conditions, and confirm the safety and effectiveness of duloxetine in 40 41 routine clinical practice. 
3 Acknowledgements:

5

6

7 The study was funded and sponsored by Lilly Deutschland $\mathrm{GmbH}$, Bad Homburg, 8

9 10 Germany. 


\section{References}

1. Abrams $P$, Cardozo L, Fall M, Griffiths D, Rosier $P$, Ulmsten U, Van Kerrebroeck $P$, Victor A, Wein A; Standardisation Sub-Committee of the International Continence Society. The standardisation of terminology in lower urinary tract function: report from the standardisation sub-committee of the International Continence Society. Urology 2003; 61: 37-49

2. Hunskaar S, Burgio K, Diokno A, Herzog AR, Hjalmas K, Lapitan MC. Epidemiology and natural history of urinary incontinence in women. Urology 2003; 62 (Suppl. 1): 1623

3. Thom D. Variation in estimates of urinary incontinence prevalence in the community: effects of differences in definition, population characteristics, and study type. J Am Geriatr Soc 1998 46: 473-480

4. Hannestad YS, Rortveit G, Sandvik H, Hunskaar S; Norwegian EPINCONT study. Epidemiology of Incontinence in the County of Nord-Trondelag. A community-based epidemiological survey of female urinary incontinence: the Norwegian EPINCONT study. Epidemiology of Incontinence in the County of Nord-Trondelag. J Clin Epidemiol 2000; 53: $1150-7$

5. Hunskaar S, Lose G, Sykes D, Voss S. The prevalence of urinary incontinence in women in four European countries. BJU Int 2004; 93: 324-30

6. Vandoninck V, Bemelmans BL, Mazzetta C, Robertson C, Keech M, Boyle P, Kiemeney LA; UREPIK study group. The prevalence of urinary incontinence in community-dwelling married women: a matter of definition. BJU Int 2004; 94: 1291-5

7. Thor KB, Katofiasc MA. Effects of duloxetine, a combined serotonin and norepinephrine reuptake inhibitor, on central neural control of lower urinary tract function in the chloralose-anesthetised female cat. J Pharmacol Exp Ther 1995; 274: 1014-24

8. Thor KB, Katofiasc MA, Danuser H, Springer J, Schaus JM. The role of 5-HT(1A) receptors in control of lower urinary tract function in cats. Brain Res 2002; 16: 290-7

9. Thor KB. Targeting serotonin and norepinephrine receptors in stress urinary incontinence. Int J Gynaecol Obstet 2004; 86 (Suppl. 1): 38-52

10. Boy S, Reitz A, Wirth B, Knapp PA, Braun PM, Haferkamp A, Schurch B. Facilitatory neuromodulative effect of duloxetine on pudendal motor neurons controlling the urethral pressure: a functional urodynamic study in healthy women. Eur Urol 2006; 50: 119-25

11. Cardozo L, Drutz HP, Baygani SK, Bump RC. Pharmacological treatment of women awaiting surgery for stress urinary incontinence. Obstet Gynecol 2004; 104: 511-9

12. Dmochowski RR, Miklos JR, Norton PA, Zinner NR, Yalcin I, Bump RC; Duloxetine Urinary Incontinence Study Group. Duloxetine versus placebo for the treatment of North American women with stress urinary incontinence. J Urol 2003; 170:1259-63. Erratum in: J Urol. 2004 171: 360 
13. Millard RJ, Moore K, Rencken R, Yalcin I, Bump RC; Duloxetine UI Study Group. Duloxetine vs placebo in the treatment of stress urinary incontinence: a four-continent randomised clinical trial. BJU Int 2004; 93: 311-8

14. Norton PA, Zinner NR, Yalcin I, Bump RC; Duloxetine Urinary Incontinence Study Group. Duloxetine versus placebo in the treatment of stress urinary incontinence. Am J Obstet Gynecol 2002; 187: 40-8

15. van Kerrebroeck P, Abrams P, Lange R, Slack M, Wyndaele JJ, Yalcin I, Bump RC; Duloxetine Urinary Incontinence Study Group. Duloxetine versus placebo in the treatment of European and Canadian women with stress urinary incontinence. BJOG $2004 ; 111: 249-57$

16. Castro-Diaz D, Palma PC, Bouchard C, Haab F, Hampel C, Carone R, Zepeda Contreras S, Rodriguez Ginorio H, Voss S, Yalcin I, Bump RC; Duloxetine Dose Escalation Study Group. Effect of dose escalation on the tolerability and efficacy of duloxetine in the treatment of women with stress urinary incontinence. Int Urogynecol $J$ Pelvic Floor Dysfunct 2006; 18:919-29

17. Bump R, Yalcin I, Voss S. The effect of duloxetine dose escalation and tapering on the incidence of adverse events (AE) in women with stress urinary incontinence (SUI). 35th Annual Meeting of the International Continence Society (ICS); 2005 Aug 28 - Sep 2; Montreal, Canada. 2005. Available from: www.icsoffice.org

18. Hurley DJ, Turner CL, Yalcin I, Viktrup L, Baygani SK. Duloxetine for the treatment of stress urinary incontinence in women: an integrated analysis of safety. Eur J Obstet Gynecol Reprod Biol 2006; 125: 120-8

19. Viktrup L, Yalcin I. Duloxetine treatment of stress urinary incontinence in women: effects of demographics, obesity, chronic lung disease, hypoestrogenism, diabetes mellitus, and depression on efficacy. Eur J Obstet Gynecol Reprod Biol 2007; 133: 105-13

20. Moore K. Duloxetine: a new approach for treating stress urinary incontinence. Int J Gynaecol Obstet 2004; 86 (Suppl. 1): 53-62

21. Federal Statistical Office of Germany. Abbreviated Life Tables. Statistical Yearbook 2008. Wiesbaden: DESTATIS; 2008. 


\section{Tables:}

5

6
7 Table $1 \quad$ Early Discontinuations

8

9

10

$11 \mathrm{~N}$

12 Early discontinuation, overall

14 Missing data

15

${ }_{16}$ Reasons for discontinuation*:

17

$$
18
$$$$
19 \text { Other }
$$

20 Surgical procedure (SUI-related) 21 Patient withdrew consent 22SUI-therapy stopped 23Patient moved house 24 Change of physician

25Lost to follow-up

26 Patient died

28

29

30

31

32

33

34

35

36

37

38

39

40

41

42

43

44

45

46

47

48

49

50

51

52

53

54

55

56

57

58

59

60 
2

3 Table $2 \quad$ Patient Characteristics 4

\begin{tabular}{|c|c|c|c|c|c|}
\hline $5-$ & & Dulox-all & Dulox-20 & Dulox-40 & Dulox-80 \\
\hline $\begin{array}{l}6 \\
7\end{array}$ & $\mathrm{~N}$ & 7887 & 2192 & 4121 & 1515 \\
\hline 8 & Mean & 61.4 & 61.8 & 61.3 & 60.8 \\
\hline $\begin{array}{l}9 \\
10\end{array}$ & Median & 62 & 62 & 62 & 62 \\
\hline 11 & SD & 12.6 & 12.8 & 12.7 & 11.8 \\
\hline $12^{\mathrm{BMI}}\left[\mathrm{kg} / \mathrm{m}^{2}\right]$ & $\mathrm{N}$ & 7873 & 2191 & 4109 & 1514 \\
\hline 13 & Mean & 27.1 & 27.1 & 27.0 & 27.3 \\
\hline $\begin{array}{l}14 \\
15\end{array}$ & $\begin{array}{l}\text { IVlean } \\
\text { Median }\end{array}$ & $\begin{array}{r}27.1 \\
27\end{array}$ & $\begin{array}{r}27.1 \\
26\end{array}$ & 26 & $\begin{array}{r}21.3 \\
27\end{array}$ \\
\hline 16 & SD & 4.3 & 4.6 & 4.2 & 4.3 \\
\hline 17 Number of child deliveries & $\mathrm{N}$ & 7828 & 2178 & 4082 & 1509 \\
\hline 18 & Mean & 2.0 & 2.0 & 2.0 & 2.0 \\
\hline 19 & Median & 2 & 2 & 2 & 2 \\
\hline 20 & SD & 1.2 & 1.2 & 1.2 & 1.2 \\
\hline 21 Duration of SUI [Months] & $\mathrm{N}$ & 7835 & 2176 & 4089 & 1511 \\
\hline 22 & Mean & 45.1 & 43.2 & 43.5 & 51.8 \\
\hline $\begin{array}{l}23 \\
24\end{array}$ & Median & 27 & 25 & 26 & 31 \\
\hline 25 & SD & 56.0 & 51.9 & 54.2 & 65.4 \\
\hline $26 \mathrm{IEF}^{*}$ per week & $\mathrm{N}$ & 7868 & 2186 & 4110 & 1513 \\
\hline 27 & Mean & 14.0 & 14.4 & 14.0 & 13.5 \\
\hline 28 & Median & 10 & 10 & 10 & 10 \\
\hline 29 & SD & 12.4 & 13.2 & 12.1 & 11.9 \\
\hline 30 Number of pads used per week & $\mathrm{N}$ & 7806 & 2167 & 4082 & 1503 \\
\hline 31 & Mean & 16.8 & 16.5 & 16.7 & 17.6 \\
\hline $\begin{array}{l}32 \\
33\end{array}$ & Median & 14 & 14 & 14 & 14 \\
\hline $\begin{array}{l}33 \\
34\end{array}$ & SD & 11.3 & 10.7 & 11.5 & 11.6 \\
\hline
\end{tabular}

$35^{*}$ incontinence episode frequency

36

37

38

39

40

41

42

43

44

45

46

47

48

49

50

51

52

53

54

55

56

57

58

59

60 
2

3 Table $3 \quad$ Type of Previous Treatment for SUI* 4

\begin{tabular}{|c|c|c|c|c|c|c|c|c|}
\hline $\begin{array}{l}5^{-} \\
6\end{array}$ & $\begin{array}{l}\text { Dulox } \\
\mathrm{N}=78\end{array}$ & & $\begin{array}{l}\text { Dulc } \\
\mathrm{N}=\end{array}$ & & $\begin{array}{l}\text { Dulox } \\
\mathrm{N}=41\end{array}$ & & $\begin{array}{l}\text { Dulox } \\
\mathrm{N}=15\end{array}$ & \\
\hline $7^{-}$ & $\mathrm{n}$ & $\%$ & $\mathrm{n}$ & $\%$ & $\mathrm{n}$ & $\%$ & $\mathrm{n}$ & $\%$ \\
\hline 8 Any specification & 4116 & 52.2 & 1079 & 49.2 & 2242 & 54.4 & 757 & 50.0 \\
\hline 10 Pelvic floor muscle training & 2975 & 37.7 & 734 & 33.5 & 1628 & 39.5 & 585 & 38.6 \\
\hline 11 Hormones local & 1431 & 18.1 & 382 & 17.4 & 795 & 19.3 & 246 & 16.2 \\
\hline 12 Homeopathy & 524 & 6.6 & 152 & 6.9 & 282 & 6.8 & 87 & 5.7 \\
\hline 13 Other & 390 & 4.9 & 105 & 4.8 & 222 & 5.4 & 59 & 3.9 \\
\hline 14Pessary & 258 & 3.3 & 61 & 2.8 & 145 & 3.5 & 49 & 3.2 \\
\hline 15Surgical procedure & 558 & 7.1 & 156 & 7.1 & 297 & 7.2 & 99 & 6.5 \\
\hline 16 Anterior colporrhaphy & 224 & 2.8 & 69 & 3.1 & 111 & 2.7 & 42 & 2.8 \\
\hline 17 Burch colposuspension & 123 & 1.6 & 32 & 1.5 & 65 & 1.6 & 24 & 1.6 \\
\hline 18 Tension free vaginal tapes & 117 & 1.5 & 33 & 1.5 & 66 & 1.6 & 17 & 1.1 \\
\hline 19 Marshall-Marchetti-Krantz & 81 & 1.0 & 27 & 1.2 & 39 & 0.9 & 14 & 0.9 \\
\hline 20 Slings & 39 & 0.5 & 13 & 0.6 & 21 & 0.5 & 5 & 0.3 \\
\hline 21 Needle suspension & 15 & 0.2 & 4 & 0.2 & 10 & 0.2 & 1 & 0.1 \\
\hline 23 Injectables & 13 & 0.2 & 6 & 0.3 & 4 & 0.1 & 3 & 0.2 \\
\hline 24 Endoscopic colposuspension & 9 & 0.1 & 4 & 0.2 & 4 & 0.1 & 1 & 0.1 \\
\hline 25 Artificial sphincters & 4 & 0.1 & 0 & 0.0 & 3 & 0.1 & 1 & 0.1 \\
\hline
\end{tabular}

26 * multiple mentioning was possible.

27
28
29
30
31
32
33
34
35
36
37
38
39
40
41
42
43
44
45
46
47
48
49
50
51
52
53
54
55
56
57
58
59
60


2

3 Table $4 \quad$ Comorbidities at Baseline* 4

$5-$

5
6
7

$7-$

8 Any specification

10 Hypertension

11 Lipid metabolism disorder

12Diabetes /Pre-Diabetes

13Heart diseases (

14Depression

15 Bronchopulmonary diseases

16 Urinary hesitancy, neurogenic

17 Coagulation disorder

18 Liver diseases

${ }_{20}$ Convulsions/seizures

21 Akathisia

$22{ }^{*}$ multiple mentioning was possible

23

24

25

26

27

28

29

30

31

32

33

34

35

36

37

38

39

40

41

42

43

44

45

46

47

48

49

50

51

52

53

54

55

56

57

58

59

60 
Adverse Events (AEs) and Serious Adverse Events (SAEs) Occurring within 12 Weeks of Observation

10

11

12

1

1

1

1

16

17

20

21

22

2

2

\section{2} 25
26

2

27

$2 \varepsilon$

2

\section{3}

3

32

33

$$
\begin{aligned}
& 3 \\
& 3
\end{aligned}
$$

$$
\begin{aligned}
& 35 \\
& 36
\end{aligned}
$$
36

3

3

40

41

42

43

44

45

46

47

48

49

50

51

52

53

54

55

56

57

58

59

60 


1
2
3
4
5
6
7
8
9

1

2

3

4 Table $6 \quad$ Types of Adverse Events Occurring within 12 Weeks of Observation

6 in $\geq 0.5 \%$ of Patients in any Duloxetine-Cohort (MedDRA Preferred Term)*

7

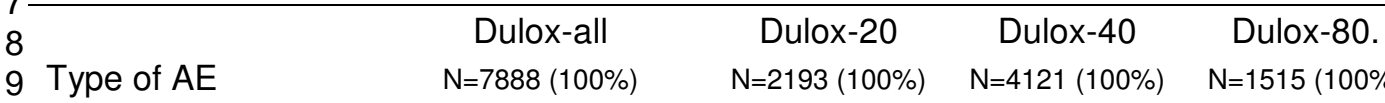

10

11 Nausea

12 Vertigo

13Dry mouth

14 Fatigue

\begin{tabular}{llllllll}
$\mathrm{n}$ & $\%$ & $\mathrm{n}$ & $\%$ & $\mathrm{n}$ & $\%$ & $\mathrm{n}$ & $\%$ \\
\hline 450 & 5.7 & 104 & 4.7 & 240 & 5.8 & 105 & 6.9
\end{tabular}

15 Headache

17 Constipation

18 Sleep disorder

19 Hyperhidrosis

20Vomiting

21 Insomnia

22Diarrhea

127

$94 \quad 1.2$

33

1.5

59

$\begin{array}{lll}1.4 & 31 & 2.0\end{array}$

$\begin{array}{lllllll}1.2 & 27 & 1.2 & 49 & 1.2 & 18 & 1.2\end{array}$

$\begin{array}{llllllll}92 & 1.2 & 19 & 0.9 & 43 & 1.0 & 30 & 2.0\end{array}$

23Restlessness

24 * multiple mentioning was possible

$\begin{array}{llllllll}82 & 1.0 & 21 & 1.0 & 42 & 1.0 & 19 & 1.3\end{array}$

$\begin{array}{llllllll}76 & 1.0 & 24 & 1.1 & 36 & 0.9 & 16 & 1.1\end{array}$

26

27

28

29

30

31

32

33

34

35

36

37

38

39

40

41

42

43

44

45

46

47

48

49

50

51

52

53

54

55

56

57

58

59

60

International Journal of Clinical Practice 
5

6

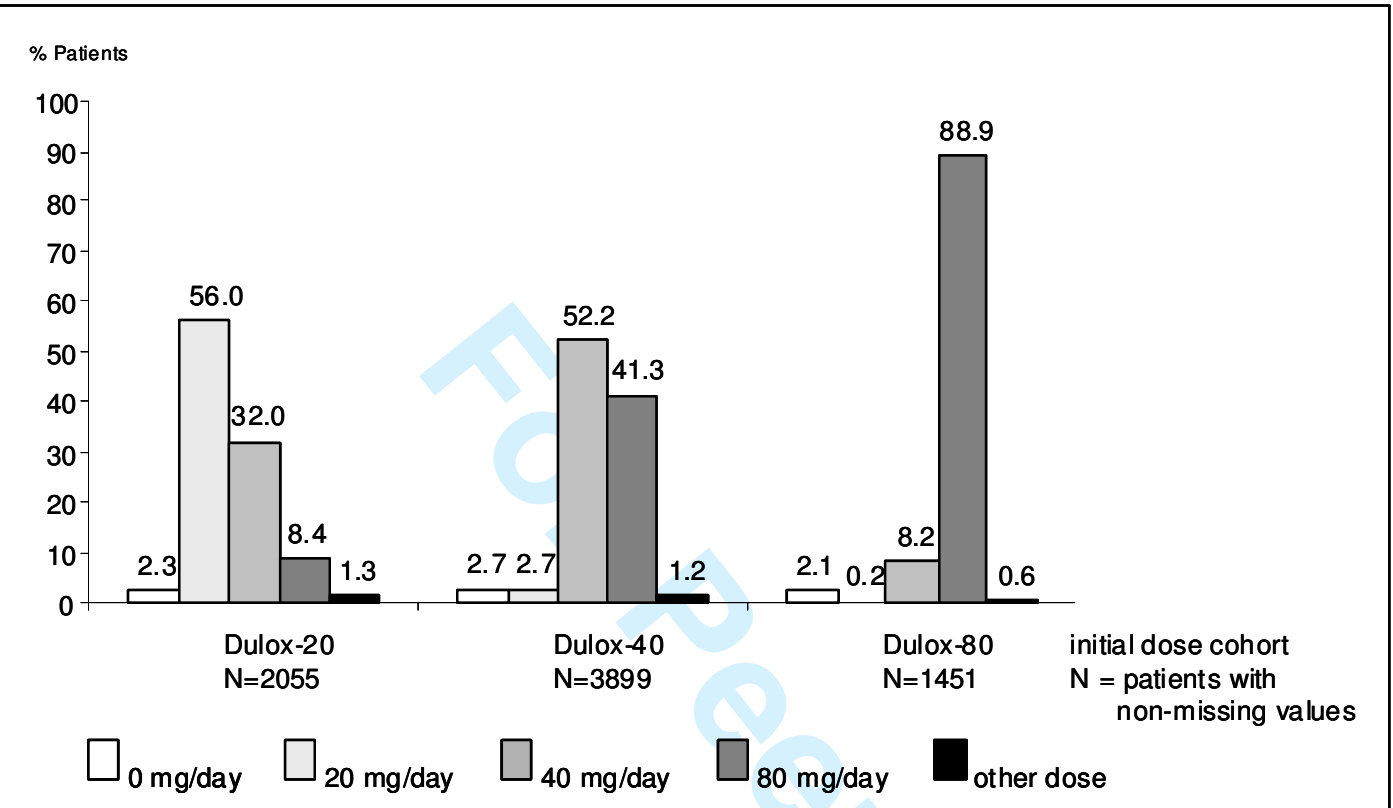

Figure 1 Doses of duloxetine at Week 12 by initial dose cohorts 
8

$\%$ Patients

0

11

12

13

14

15

16

17
18
18

18
19

20

21

2

23

24

25

26

27

28

29

30

31

32

33

34

35

36

37

38

39

Figure 2 Perceived change in SUI episode frequency at Week 12 (compared to baseline) 


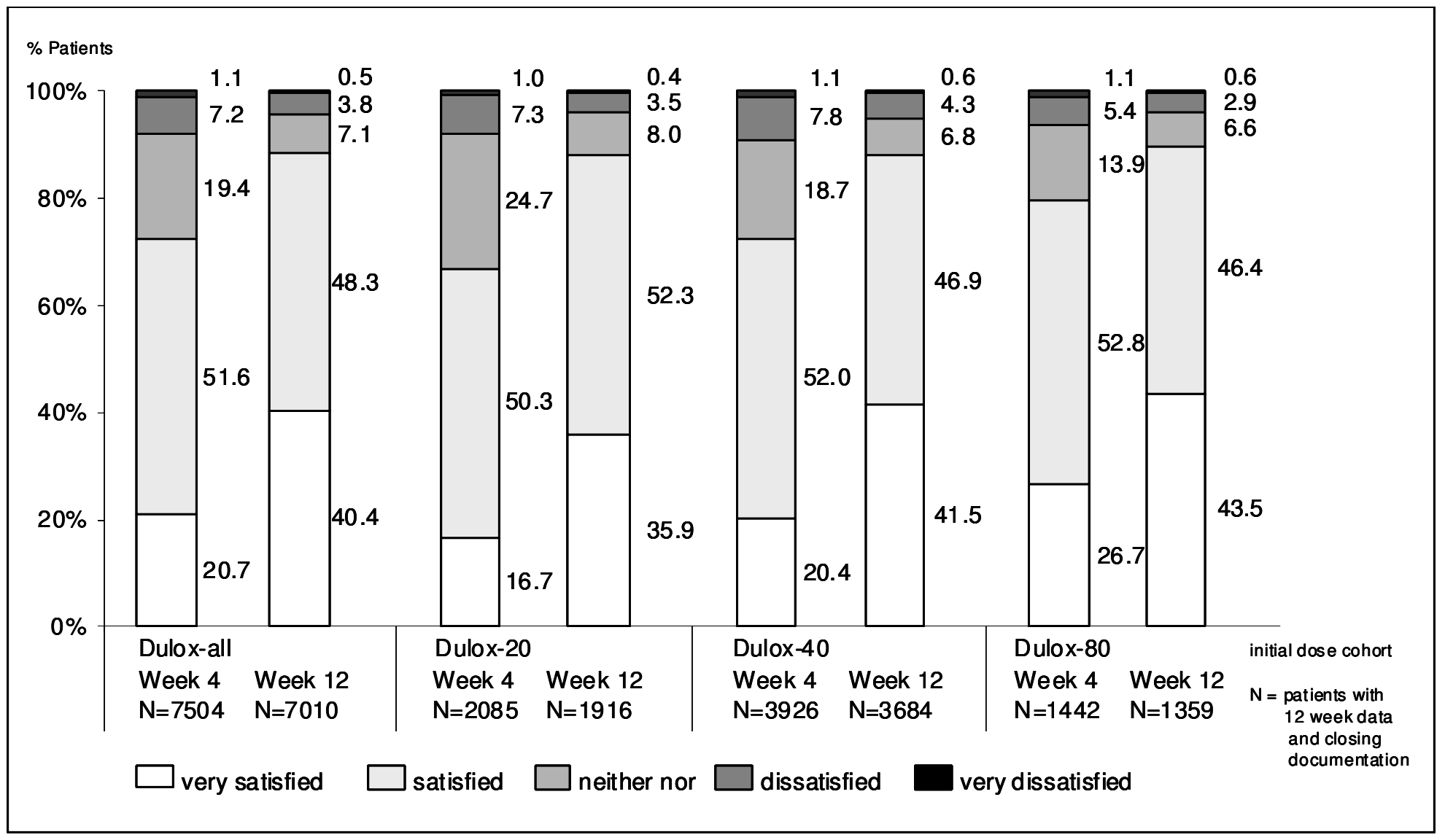

Figure 3 Patient satisfaction at Week 4 and Week 12 